\title{
Therapeutic reintubation for post-intubation laryngotracheal injury in preterm infants
}

\author{
L.J. Hoeve*, O. Eskici, C.D.A. Verwoerd \\ Department of Otorhinolaryngology, Sophia Children's Hospital, Erasmus University Rotterdam, \\ Dr. Molewaterplein 60, 3015 GJ Rotterdam. The Netherlands
}

Received 26 October 1993; revision received 25 April 1994; accepted 29 April 1994

\begin{abstract}
The failure to extubate a preterm infant after prolonged intubation is often caused by laryngotracheal injury. This condition is treated by tracheotomy, anterior cricoid split, or often, by reintubation and subsequent extubation attempts in a later stage. To assess the value of reintubation as treatment of post-intubation injury, we retrospectively studied a group of preterm infants from the neonatal intensive care unit in the Sophia Children's Hospital. Three categories of injury were distinguished according to the findings at laryngobronchoscopy: (a) edema or superficial lesions, (b) ulcerations and edema and (c) granulations. Twenty-three infants were therapeutically reintubated after post-intubation injury was diagnosed, for a mean period of 17 days. The therapy was successful in 22 patients, and a failure in one. The followup period was a mean 34 months. The result and the duration of the treatment vary with the category of the injury and the condition of the patient. Therapeutic reintubation is compared with alternatives such as anterior cricoid split and tracheotomy. We conclude that reintubation is a valuable therapy that should precede the decision for surgery.
\end{abstract}

Keywords: Prolonged intubation; Preterm infants; Post-intubation injury; Therapeutic reintubation

\section{Introduction}

Prolonged intubation and artificial ventilation play an important part in present neonatal intensive care. Pathological changes in the larynx or trachea following prolonged intubation have been reported in 74-100\% of the autopsied neonates. In surviving neonates severe airway injury, including ulceration and granulation, occurs

${ }^{*}$ Corresponding author. 
in $44-47 \%$, and subglottic stenosis in $0.7-9 \%[8,9,11,19]$. These injuries may result in failure to extubate the patient. The condition can be diagnosed and categorized by rigid laryngobronchoscopy and then treated by reintubation, tracheotomy, or anterior cricoid split [1,3-5].

The present retrospective study concerns the efficacy of therapeutic reintubation in a group of preterm infants in whom extubation had failed, as a result of endoscopically confirmed post-intubation injury of the larynx or trachea.

\section{Materials and methods}

The study group consisted of 23 consecutive preterm infants ( 15 male, 8 female), admitted to the Neonatal Intensive Care Unit (NICU) of the Sophia Children's Hospital, Rotterdam, The Netherlands, between 1982-1990 [16]. The selection criteria were prolonged intubation and artificial ventilation resulting in an intubation injury and confirmed and categorized by laryngobronchoscopy with rigid telescopes under general anesthesia in the operating theatre [1]. All patients were treated by reintubation.

The mean postconceptual age of the patients at birth was 30 weeks $(25-36)$. The patients had been intubated and artificially ventilated for respiratory insufficiency, hyaline membrane syndrome, diaphragmatic hernia, patent ductus arteriosus or cyanotic spells. Intubation had lasted a mean 34 days (3-114), and artificial ventilation a mean 25 days (1-102) (Table 1). When they could breath spontaneously, ventilation was stopped and extubation was attempted, but proved to be unsuccessful (Fig. 1) Subsequent laryngobronchoscopy demonstrated the cause of this failure to be laryngeal or tracheal injury related to prolonged intubation. The lesions narrowing the airway were classified into one of the following categories: (a) edema and/or superficial lesions of the (sub)mucosa, (b) deep ulceration of perichondrium and cartilage, and edema or (c) granulation tissue. The laryngotracheal injury was subsequently treated by nasotracheal reintubation, without artificial ventilation. A PVC tube was used in 22 patients, and a siliconized silicone rubber tube in the remaining one [2]. The size of the tube was 'loose fit', permitting leakage of air at the end of an insufflation. After some time (Fig. 1) extubation was reattempted. Every attempt of extubation was preceded and followed by intravenous administration of dexamethasone.

Subsequently the category of pathology determined by laryngobronchoscopy, and the outcome of therapeutic reintubation were studied.

Table 1

Duration of intubation and artificial ventilation preceding the diagnosis of post-intubation injury at laryngobronchoscopy

\begin{tabular}{lrllll}
\hline & \multicolumn{1}{c}{$n$} & \multicolumn{2}{c}{ Intubation days } & \multicolumn{2}{c}{ Ventilation days } \\
\hline All patients & 23 & 34 & $(3-114)$ & 25 & $(1-102)$ \\
Edema (a) & 9 & 24 & $(3-102)$ & 23 & $(1-102)$ \\
Ulcerations (b) & 3 & 22 & $(16-30)$ & 22 & $(16-29)$ \\
Granulations (c) & 11 & 45 & $(7-114)$ & 28 & $(2-55)$ \\
\hline
\end{tabular}




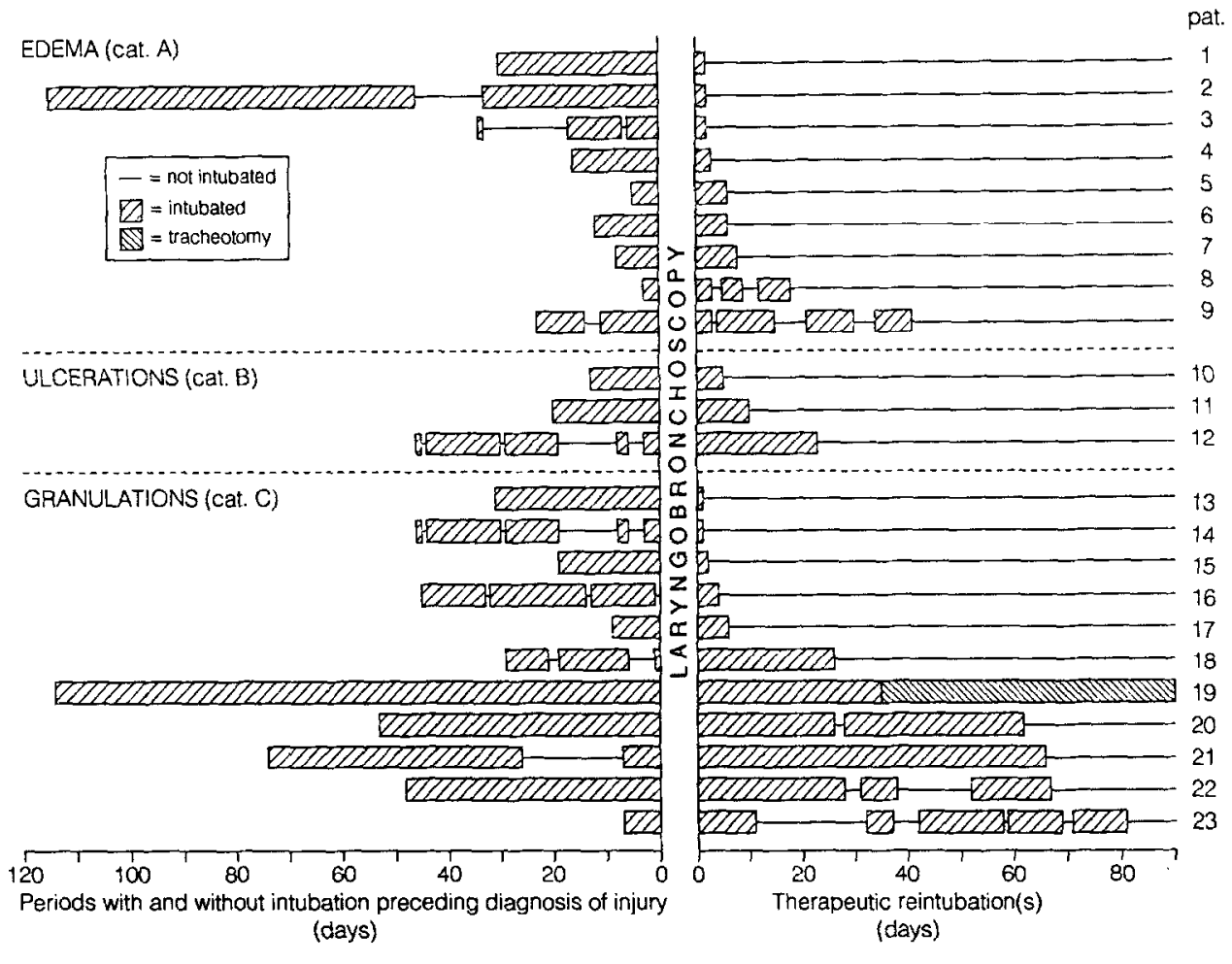

Fig. 1. Periods with and without intubation since birth, before and after the diagnosis of intubation injury. The patients have been divided into 3 categories of injury: (a) edema or superficial lesions, (b) ulcerations and edema and (c) granulations. (The periods without intubation are only shown if they lasted more than $12 \mathrm{~h})$.

\section{Results}

The mean age of the 23 infants at laryngobronchoscopy was 37 days (3-115).

Edema or superficial lesions (category a) of the glottis and the subglottic area were found in 9 patients.

Ulcerations and edema (category b) were observed in 3 patients at the glottic and subglottic level. Posterior parts of the cricoid cartilage were not covered by mucosa or perichondrium and exposed to the airway.

Granulation tissue (category c) was present in 11 patients. The granulations involved the glottis in 4 patients, the subglottis in 3 , both glottis and subglottis in 2 , and the trachea in 2 patients. In 10 of these 11 patients extensive granulation tissue completely obstructed the lumen due to a circular localization. The other patient had a left sided subglottic cyst and granulations.

\subsection{Therapeutic reintubation and final extubation}

In 17 patients the first extubation attempt was successful, in 5 others 2 or more 
Table 2

Results and duration of therapeutic reintubation in preterm infants with post-intubation laryngeal or tracheal injury

\begin{tabular}{lrlrrl}
\hline & $n$ & Result & $n$ & \multicolumn{2}{c}{ Days intubation } \\
\hline All patients & 23 & Cured & 22 & 17 & $(1-66)$ \\
& & Failed & 1 & 35 & \\
Edema (a) & 9 & Cured & 9 & 8 & $(2-30)$ \\
Ulcerations (b) & 3 & Cured & 3 & 13 & $(5-23)$ \\
Granulations (c) & 11 & Cured & 10 & 27 & $(1-66)$ \\
& & Failed & 1 & 35 & \\
\hline
\end{tabular}

attempts were necessary. Eventually 22 infants were successfully extubated, after a mean reintubation period of 17 days [1-66] (Table 2). One patient needed a tracheotomy when reintubation apparently failed as a result of extensive circular subglottic granulations. He could be decannulated 4 months later without any further treatment.

All nine patients with edema or superficial lesions (category a) could be extubated after a mean reintubation period of 8 days (2-30), the 3 with ulcerations (category b) after a mean 13 days (5-23). In the group with granulation tissue (category c) 10 out of 11 patients were finally extubated after a mean 27 days (1-66). The only remaining patient had a tracheotomy (Table 2).

\subsection{Complications}

Complications of therapeutic reintubation occurred in 10 out of 23 patients. The complications were: pulmonary infection in 8, accidental extubation in 8, laryngeal granulations in 2, aspiration in 2, tube obstruction in 1 and feeding problems in 1 patient. Three patients needed artificial ventilation for a few days because of a pulmonary infection.

\subsection{Late results}

The mean follow-up period of the 22 successfully treated patients is 34 months (4-68). Seventeen patients showed no signs of airway disorder. Five patients, all originally categorized in the granulations group (c), had minor complaints that could point to laryngeal dysfunction (Table 3). One patient (no. 18) still demonstrates a slightly audible inspiration on exertion only after 65 months. A second (no. 23) has an audible inspiration on exertion and hoarseness after 36 months. The third (no. 15) had one minor episode of pseudocroup (a respiratory tract infection with inspiratory stridor, but no need for intubation) one year after extubation, but no complaints 18 months since then. The fourth (no. 17) had a few episodes of pseudocroup during the follow up period of 26 months after extubation, but has been lost to follow up for 5 years now. The problems of these 4 patients did not necessitate another laryngoscopy. The fifth patient (no. 13), demonstrated a slowly progressive inspiratory stridor for many years. Laryngobronchoscopy 5 years after extubation revealed a stricture in the posterior commissure of the glottis/subglottis, leaving a lumen of $4 \mathrm{~mm}$. Further treatment will probably be necessary in this case. 
Table 3

Patients with complaints during the period of follow-up

\begin{tabular}{llllc}
\hline Pat & Category & Follow-up disorders & $\begin{array}{l}\text { Follow-up } \\
\text { duration (m) }\end{array}$ & LBS \\
\hline 13 & c & stricture post. comm. & 60 & + \\
15 & c & pseudocroup $1 \mathrm{x}$ & 30 & - \\
17 & $\mathrm{c}$ & pseudocroup $\pm 3 x$ & 26 & - \\
18 & $\mathrm{c}$ & audible inspiration on exertion & 65 & - \\
23 & $\mathrm{c}$ & audible inspiration on exertion, hoarseness & 36 & - \\
\hline
\end{tabular}

LBS, laryngobronchoscopy; pseudocroup is defined as a respiratory tract infection with inspiratory stridor and no need for intubation.

\section{Discussion}

Edema or superficial lesions (category a) in infants are generally treated by intubation or tracheotomy [6,18]. There is no consensus about the optimal treatment of ulcerations (category b) and granulations (category c). Besides tracheotomy, intubation [10], removal of granulations with a forceps or laser surgery [17] or anterior cricoid split [6], have been advocated.

The present study demonstrates that the majority of preterm infants with postintubation edema, (sub)mucosal lesions, ulcerations and granulations can be cured with therapeutic reintubation, thus avoiding a tracheotomy and further surgery.

Extubation was successful in the 12 patients with category (a) and (b) lesions (superficial lesions, edema and ulcerations) after a relatively short period of reintubation (means of 8 and 13 days, respectively). Interestingly ulcers appeared to heal within a few weeks even with an endotracheal tube in place, which confirms previous observations $[9,15]$.

Nearly half of the patients with category (a) injury were successfully extubated within 3 days (Fig. 1). Therefore it seems advisable to attempt a first extubation in this group of patients after 2 or 3 days. If the extubation does not succeed, the next attempts should be spaced according to the findings at laryngobronchoscopy, and the observation of the respiration between extubation and reintubation.

In case of ulceration and associated edema (category b) extubation can be attempted after 3-7 days, depending on the severity of the injury. Attempts may be repeated at weekly intervals and should be successful within 4 weeks. If the treatment is not successful in that period tracheotomy should be performed.

For granulations (category c) the success rate was less, 10 out of 11 patients could be extubated, while the period of reintubation was longer ( 27 days). Secondary stenosis 5 years after the final extubation was observed in a patient from category c. Fivc of the 10 successfully treated patients with granulations (category c) were extubated within 10 days. The other 5 needed a longer period of intubation (Fig. 1). We suggest attempting extubation after about 10 days of therapeutic reintubation and repeat this at intervals of the same duration. The maximum period of therapeutic intubation in category $c$ patients depends on factors as respiratory infections, feeding difficulties, and the involution of the granulations. 
Alternatives for therapeutic reintubation in categories (b) and (c) are tracheotomy and anterior cricoid split.

A tracheotomy is less unpleasant to the infant than an endotracheal intubation. However, the complication rate $(60 \%)$ of a tracheotomy in preterm infants is higher than in full-term infants $(40 \%)$ [13], while the mortality in infants is $0-5 \%[12,13]$. Reported complications are pneumothorax, accidental decannulation, tube obstruction, granulation tissue, tracheomalacia, tracheal stenosis and hemorrhage [7,12-14]. The complication rate in our patients was $43 \%$ with no mortality. In our view tracheotomy is indicated if therapeutic intubation appears to fail.

The anterior cricoid split is not indicated in patients with minor laryngeal injury or ulcerations $[3,5,6]$. Anterior cricoid split appears in our experience less successful if fresh granulation tissue is present. The operation induces further granulation formation and delays extubation. The operation seems useful in intubated infants with 'old' granulations or mild subglottic stenosis, in the absence of respiratory tract infection. Therefore we prefer intubation to anterior cricoid split in patients with granulations.

\section{Conclusions}

Therapeutic reintubation is the treatment of choice in preterm infants with edema, superficial lesions, or ulceration (categories a and b) of the larynx or trachea. Therapeutic reintubation is less successful in patients with granulations, but the alternatives tracheotomy and anterior cricoid split have important disadvantages.

Intubation injury in preterm infants is therefore preferably treated with reintubation. If that treatment fails, or if the infant's tolerance does not permit continuation of the intubation, tracheotomy is indicated. Anterior cricoid split is only considered in the case of old granulations.

\section{References}

[1] Benjamin, B. (1993) Prolonged intubation injuries of the larynx: endoscopic diagnosis, classification and treatment. Ann. Otol. Rhinol. Laryngol. Suppl. 160.

[2] Berkovits, R.N.P., Van der Schans, E.J. and Molenaar, J.C. (1987) Treatment of congenital cricoid stenosis. Progr. Pediatr. Surg. 21, 20-28.

[3] Cotton, R.T. and Seid, A.B. (1980) Management of the extubation problem in the premature child: anterior cricoid split as an alternative to tracheotomy. Ann. Otol. 89, 508-511.

[4] Cotton, R.T. (1985) Prevention and management of laryngeal stenosis in infants and children. J. Pediatr. Surg. 20, 845-851.

[5] Cotton, R.T., Myer, C.M., Bratcher, G.O. and Fitton, C.M. (1988) Anterior cricoid split, 1977-1987: evolution of a technique. Arch. Otolaryngol. Head Neck Surg. 114, 1300-1302.

[6] Cotton, R.T., Management and prevention of subglottic stenosis in infants and children. In: Bluestone, C.D., Stool, S.E. and Scheetz, M.D. (Eds.), Pediatric Otolaryngology, 2nd Edn., WB Saunders Company, Philadelphia, 1990, pp. 1194-1204.

[7] Crysdale, W.S., Feldman, R.I. and Naito, K. (1988) Tracheotomies: a 10-year experience in 319 children. Ann. Otol. Rhinol. Laryngol. 97, 439-443.

[8] Dankle, S.K., Schuller, D.E. and McClead, R.E. (1986) Risk factors for neonatal acquired subglottic stenosis. Ann. Otol. Rhinol. Laryngol. 95, 626-630. 
[9] Dankle, S.K., Schuller, D.E. and McClead, R.E. (1987) Prolonged intubation of neonates. Arch. Otolaryngol. Head Neck Surg. 113, 841-843.

[10] Dinwiddie, R. (1989) A respiratory physician's view of acquired subglottic stenosis. J. Laryngol. Otol. Suppl. 17, 31-34.

[11] Fan, L.L., Flynn, J.W. and Pathak, D.R. (1983) Risk factors predicting laryngeal injury in intubated neonates. Crit. Care Med. 11, 431-433.

[12] Gaudet, P.T., Peerless, A., Sasaki, C.T. and Kirchner, J.A. (1978) Pediatric tracheostomy and associated complications. Laryngoscope 88, 1633-1641.

[13] Gianoli, G.J., Miller, R.H. and Guarisco, J.L. (1990) Tracheotomy in the first year of life. Ann. Otol. Rhinol. Laryngol. 99, 896-901.

[14] Gibson, R. and Byrne, J.E.T. (1972) Tracheotomy in neonates. Laryngoscope 82, 643-650.

[15] Gould, S.J. and Graham, J. (1989) Long term pathological sequelae of neonatal endotracheal intubation. J. Laryngol. Otol. 103, 622-625.

[16] Hoeve, L.J. and Rombout, J. (1992) Pediatric laryngobronchoscopy: 1332 procedures stored in a database. Int. J. Pediatr. Otorhinolaryngol. 24, 73-82.

[17] Holinger, L.D. (1982) Treatment of severe subglottic stenosis without tracheotomy. Ann. Otol. Rhinol. Laryngol. 91, 407.

[18] Latto, I.P, and Rosen, M. (1985) Complications of tracheal intubation. In: Latto, I.P. and Rosen, M. (Eds.), Difficulties in Tracheal Intubation, Ballière Tindall, London, pp. 36-47.

[19] Strong, R.M. and Passy, V. (1977) Endotracheal intubation: complications in neonates. Arch. Otolaryngol. 103, 329-335. 